\title{
Collaborative Musical Creativity between Students and Adults: The Sonorous Paella
}

\author{
Adolf Murillo', María Elena Riaño2 ${ }^{2}$ and Alfredo Bautista ${ }^{3}$ \\ 1 Universitat de València, Departament de Didàctica de l'Expressió Musical, Plàstica i Corporal, València, Spain \\ 2 Universidad de Cantabria, Departamento de Educación, Santander, Cantabria, Spain \\ 3 The Education University of Hong Kong. Department of Early Childhood Education, Hong Kong, SAR, China
}

\begin{abstract}
While creativity is a key element of contemporary curriculum frameworks around the world, it is still insufficiently fostered in formal education settings. This study analyzes a project for collaborative musical creativity, entitled The Sonorous Paella. Participants ( $N=12$ ) were eight Year 4 secondary students, two professional musicians, an artist-in-residence, and a music teacher. Drawing on a graphic musical score, the participants worked together for 1.5 months to produce a group composition and performance. They were provided with various sound producers (instruments, everyday objects, technological devices) and were encouraged to flexibly utilize the physical space to maximize collaborative participation. Field notes and pictures taken during working sessions and rehearsals, audio recordings from the final concert, and individual interviews with all participants were qualitatively analyzed. In response to the three study objectives, we conclude that: (1) the design of this collaborative project was consistent with current researchbased creativity discourses; (2) drawing on the quality and originality of the final concert, the project fostered the musical creativity of the group; and (3) participants' perceptions of and opinions about their creativity learn-
\end{abstract}

ing processes were unanimously positive. Our final aim is to inspire music teachers in designing curriculum units that foster collaborative musical creativity.

\section{KEYWORDS:}

collaborative musical creativity, graphic scores, music technology, music teacher education, secondary education

\section{Funding statement}

This study was conducted within the scope of the Valencia Music Art Marget (2016-2019) project, AC2016-es-0012 - Claves, funded by Fundación Daniel \& Nina Carasso. We would like to thank all participants for their positive disposition, as well as IES Arabista Ribera for facilitating the implementation of The Sonorous Paella.

\section{Article history:}

Received: March 2, 2021

Received in revised from: April 15, 2021

Accepted: April 20, 2021

ISSN 2354-0036

DOI: $10.2478 /$ ctra-2021-0016

\section{Corresponding author at:}

María Elena Riaño

E-MAIL: elena.riano@unican.es 


\section{INTRODUCTION}

Creativity is present in contemporary curriculum frameworks around the world and it is an integral part of action plans by international educational organizations. For example, the United Nations Educational, Scientific and Cultural Organization (UNESCO, 2014) states that education should contribute to foster students' creative thinking, which is defined as the ability to "apply their imagination to generating ideas, questions and hypotheses, experimenting with alternatives, and to evaluating their own and their peers' ideas, final products and processes" (p. 6). Similarly, the Organization for Economic Co-operation and Development (OECD) conceptualizes creativity as a competence that transcends disciplinary boundaries and that is essential for life-long learning. Their project, entitled The Future of Education and Skills 2030, focuses on the design of curriculum frameworks to enhance students' creativity and creative thinking (OECD, 2018). Because the world undergoes rapid changes and constant transformation, it is widely understood that education systems need to prepare all students (from early childhood to postsecondary education) to think out-of-the-box and find innovative solutions that benefit everyone (Runco, 2007; Runco \& Jaeger, 2012).

This article focuses specifically on collaborative musical creativity at a secondary school level. In recent years, the notion of collective creativity has acquired great prominence in contemporary educational ecosystems and in the scholarly literature, both general (Kelly, 2020) and specific to music education (Muhonen, 2014; Veloso, 2017). Following Muhonen (2014), we conceptualize collaborative musical creativity as:

[...] a process and inquiry in which each participant's intentions, experiences, knowledge, and social skills are present in collective negotiation (non-verbal, verbal, musical) where there is a possibility for tactful scaffolding during the creation process that aims toward a consensus of a shared goal, a new song, that its creator experience as meaningful (p. 192).

Despite the push for collaborative creativity in the music classroom, research shows that many music teachers find it challenging to design and implement curriculum units that foster collective exploration, experimentation and creation. For example, Tan, Yukiko, Oie, and Mito (2019) have recently argued that music teachers today continue to deliver old-fashioned instruction and that it is urgent to support them to improve their creativity-fostering pedagogical practices. The question of how we create educational environments and curriculum units that are conducive to collaborative creative development in the music classroom, therefore, needs to be further explored.

The present study responds to this call. We analyze a project for collaborative musical creativity recently implemented in Valencia (Spain), entitled The Sonorous Paella. The project, which spanned 1.5 months, was based on a traditional recipe of the Spanish cuisine: the Valencian paella (also known as seafood rice). Consistent with the recommendations to engage different actors in creativity projects (Hall \& Thomson, 2017), the participants in the experience included secondary school students as well as adults (i.e., professional musicians, an artist-in-residence, and a music educator). In the paper, we analyze (1) the project's design characteristics and how it was imple- 
mented, (2) the sonorous outcome of The Sonorous Paella, as performed in a final concert, and (3) the participants' perceptions of and opinions about their creativity learning processes during the project. Our final aim is to inspire music teachers in designing curriculum units that foster collaborative musical creativity.

In the next section, we first review the literature centered on the elements that hinder the development of students' musical creativity in formal education settings. Subsequently, we review research on key pedagogical strategies that promote musical creativity. Finally, we present the study objectives and justify their relevancy.

\section{LITERATURE REVIEW}

\section{Elements that Hinder the Development of Musical Creativity}

The literature indicates that there are multiple factors that hinder development of creativity (both individual and collective) in contemporary music classrooms. Firstly, there is evidence that many music teachers lack a clear understanding of the meaning of creativity applied to music education (Martin \& Wilson, 2017). For example, Kokotsaki (2011) found that prospective secondary school music teachers do not regard musical creativity as an intended learning objective because, in their view, creativity emerges spontaneously. While these music teachers thought of creativity as a vital component in students' development, they did not plan learning experiences involving musical exploration, improvisation, collaborative work, nor did they design strategies to assess musical creativity (Kokotsaki, 2011). Research conducted with teachers of other subjects has also shown that while creativity is highly valued, teachers' conceptions of this notion are rarely theoretically grounded and their pedagogies seldom reflect research-based recommendations (Mullet, Willerson, Lamb, \& Kettler, 2016). For instance, Runco (2007) found that teachers tend to associate creativity with concrete final learning outcomes and underestimate the importance of the creative processes experienced by students.

Another element that hinders creativity-fostering pedagogies in the music classroom is teachers' lack of preparation in musical creativity (Bautista, Toh, Mancenido, \& Wong, 2018; Veloso, 2017). In many countries, music teachers only receive classical musical training, which according to Lines (2009) often results in traditionalist views of music education. Classically trained teachers tend to prioritize reproduction (music theory, solfege, skills, techniques, classical repertories) over creativity (sound exploration, improvisation, composition), rarely exposing students to open-ended activities (Tan et al., 2019). Johnson (2009) claimed that offering classical music training in schools may be counter-productive, as students could not able to connect what they learn with their actual musical preferences, interests, and needs.

The way in which music notation is utilized has also been described as an element that hinders musical creativity (Bergstrom-Nielsen, 2010; Brondum, 2018). Many music educators focus exclu- 
sively on teaching the standard music notational system, without introducing students to other kinds of unconventional or invented notations, which leads to reproductive practices (Lines, 2009). Other teachers do incorporate alternative music notations, but they do not fully utilize their creative potential. For example, Elkoshi (2015) found that unconventional notations are often employed simply to ask students to transcribe or represent existing music (e.g., popular songs, classical pieces), rather than as a trigger for sound exploration, experimentation, and creation, as we do in the present study.

Finally, another element that hinders musical creativity has to do with the availability of and accessibility to Information and Communication Technologies (ICT), and with how ICT are used for music teaching and learning (Hoffmann, Ivcevic, \& Brackett, 2016) and as tools to think or create (Creely, Henriksen, \& Henderson, 2020). Research shows that ICT are often imposed into musical activities, where there is no room for students' imagination, using them as tools to achieve traditional learning outcomes (e.g., producing scores with music notation software). Burnard, Murphy, and Akuno (2017) have argued that the use of ICT in formal music education settings tends to be rather conservative and reproductive, while it is significantly more productive and creative in non-formal and informal settings. This is consistent with Delalande (2008), who showed that technological advances have higher repercussion outside formal music education, where the number of music amateurs and innovative approaches to music creation continues to grow rapidly. For all these reasons, music researchers and teacher educators currently agree that ICT devices such as computers, mobile phones, and tablets should be integrated as basic components in compulsory music education (Cobo, 2016).

\section{Pedagogical Keys to Foster Musical Creativity}

This section elaborates on a series of pedagogical keys that, according to the specialized literature, contribute to foster students' musical creativity. Note that the design of The Sonorous Paella project was guided by the studies reviewed below. In a review of the literature published between 1990 and 2018, Cremin and Chappell (2019) identified seven interrelated components of creativity-fostering pedagogies: generation and exploration of ideas, fostering autonomy and agency, students' play, problem-solving, risk-taking, co-construction of knowledge and collaboration, and teachers' own creativity. The authors recommended music teachers to "join researchers as co-participants, in order to enable a more layered examination of the impact of creative pedagogies on student creativity" (Cremin \& Chappell, 2019, p. 27). In addition to researchers' support, the implementation of creativity-fostering pedagogies also requires involvement of educational institutions. As argued by Dezuanni and Jetnikoff (2011), it is essential for school leaders and administrators to allow more flexibility in curriculum, provide teachers and students with adequate spaces and resources, and encourage innovative teaching and learning classroom dynamics.

Numerous studies have shown that musical creativity is more likely to emerge when classroom activities require collaboration and active participation (Bautista, Tan, Ponnusamy, \& Yau, 2016; Muhonen, 2014; Veloso, 2017). For example, Sawyer (2007) found that student social interaction 
leads to deeper learning processes and better outcomes, enhancing both musical competencies and performance quality. This author proposed a model of collaborative creativity based on social psychology theories and a deep ethnographic study on music improvisation. In the same vein, Tan et al. (2019) stated that research and practice in musical creativity require shared efforts between students and educators. Furthermore, researchers have suggested that musical creativity is even more likely to emerge when students collaborate with various experts (Zhang, Li, \& Yan, 2020). For example, Lage and Cremades (2019) conducted an action-research collaborative project that involved secondary school students, artists, researchers, and teachers. Adopting artography (Irwin, 2013) as a framework, the authors found that music creative spaces are determined by various interconnected factors, including active involvement and wellbeing, emergence of group flow and positive emotions, and high levels of motivation. These findings have profound educational implications and contribute to a better understanding of group improvisation and musical creativity as a dialogic practice (Bautista et al., 2018). Such implications resonate with Ruokonen (2018), who showed that artistic projects involving artists, teachers, and students working together have the potential to enhance development of creative thinking and well-being.

Recent research has also shown that unconventional music notation is a powerful resource to foster musical creativity. In the study by Brondum (2018), participants expressed that the use of unconventional graphic notation was beneficial in terms of supporting collaborative processes and providing inspiration to create an original musical piece, taking into consideration the composer's central idea. The use of unconventional notation contributed to making the activity open-ended for students, which led to freedom to compose imaginatively and without inhibitions. Moreover, there is evidence that the use of unconventional notation enhances students' active listening (Reybrouck, Verschaffel, \& Lauwerier, 2009), as well as conceptual and structural understanding of music (Bergstrom-Nielsen, 2010). Another key resource to boost musical creativity involves the use of spaces that facilitate social interactions (Vecchi, 2010). According to Hemlin, Allwood, and Martin (2008), the extent to which an individual's or a group's creative potential is expressed depends considerably on the environment in which they work. Environments must be adaptable and flexible, allowing easy accessibility to materials and resources (Nouri \& Farsi, 2018). For example, in the study by Beghetto and Kaufman (2014), teachers created this kind of environment by adopting a play-based approach in the classroom. The teachers fostered open dialogues and utilized the space to allow flexible learning experiences for students.

Finally, strategic use of ICT is another pedagogical key to foster musical creativity (Hoffmann et al., 2016). Because ICT allow to generate sounds from all kinds of instruments, introduction of devices such as computers, smartphones, iPods and iPads in music education classrooms has widened students' creative possibilities (Martin, 2013). Corradini (2011) argued that technologies can expand our perception, functioning as tools for thinking in sound. De Vries (2016) has even argued that ICT should be seen as much more than tools, as they allow students to develop specific technological knowledge, highly relevant in today's world. Nielsen (2013) investigated students' and teachers' perceptions of a high school music technology curriculum. The study concluded by call- 
ing for more research on how music technology may enhance collaboration within musical creativity projects, with a special focus on the subjective perceptions of participants in such projects. The present study responds to this call.

\section{Objectives of the Present Study}

This paper analyzes The Sonorous Paella (in Spanish, La Paella Sónica), a project for collaborative musical creativity recently implemented in Valencia (Spain). The study has three objectives. Objective 1 is to analyze the design characteristics of the project. A deep description of the project's design characteristics will inspire teachers in designing curriculum units that foster collaborative musical creativity. Objective 2 is to describe the sonorous outcome of The Sonorous Paella, as performed in the final recital by the project participants, as a result of their creative collaborative process. We analyze the decisions agreed upon by participants during various rehearsals. Finally, Objective 3 is to analyze the participants' perceptions of and opinions about their collaborative learning processes in this sound-creation project. Knowing the perspectives of participants may be useful for teachers interested in trying out similar creativity units in their classrooms.

\section{METHOD}

\section{Research Context}

The study was carried out in a Compulsory Secondary Education (CSE) public school in Valencia. CSE in Spain comprises four academic years (from 12 to 16 years of age). The current national curriculum includes Music as a compulsory subject in Years 1-3, and optional in Year 4. In Spain, regulatory competencies for Education are shared between the State and the various Autonomous Communities. The Valencian Community is a region with an internationally recognized musical tradition, with more than 600 elementary music schools, 50 professional conservatories, and three university-level music schools. Due to the regional passion for music, the number of hours devoted to Music in Valencian CSE public schools is higher than the national average.

The school where the study was conducted was plurilingual, with Spanish, Catalan and English as official mediums of instructions. It had 505 CSE students representing more than 30 nationalities, mainly from medium/low socio-economic status. The school's Music Department had a tracked history of implementing units for creativity development and project-based learning.

\section{Participants}

Twelve participants engaged in the collaborative project: eight Year 4 CSE students, the majority with no prior formal musical training (five female and three male students, ranging from 16 to 17 years of age), two professional musicians (female flutist and male percussionist, 40 and 53 years of age, respectively), an artist-in-residence (22-year-old male), and a music educator (46-year-old 
female). The first author of this article was the designer of the graphic score and adopted the role of participant observer.

\section{Research Design and Data Sources}

We used an ethnographic research design and a qualitative analytic approach (Creswell, 2013). To address Objectives 1 and 2, we collected field notes and pictures during all working sessions and rehearsals. The participant observer focused attention on musical aspects (e.g., sound productions linked to specific symbols from the graphic score, exploration and experimentation strategies, technical difficulties in performance), documented the use of ICT resources, as well as how the classroom layout changed throughout the project. We also audio recorded the final concert (audio tracks are presented in Results). To address Objective 3, individual interviews with all participants were conducted. Drawing on the field notes, we designed a semi-structured protocol of openended questions referred to the following topics: degree of collaboration between students and adults, collaborative contributions and solutions, level of openness to contemporary musical languages, opinions about the graphic score utilized as a creative trigger, use of ICT in music creation, and perceptions about the role of physical space as a facilitator of creativity.

\section{Procedure}

Participation was voluntary. All participants signed consent forms and were informed about the calendar of events prior to the first working session. The participant observer adopted the role of a mediator during the creative process. While actively interacting with the participants, the observer did not take part in decision-making processes, focusing instead on documenting emerging ideas and the decisions participants made. The information gathered from field notes allowed us to design the interview protocol. With the ethical approval and consent of the school's Principal, the observer interviewed the 12 participants after the final concert. Interviews ranged from 20 to 30 minutes and were conducted within the span of a week. Interviews were audiotaped and then transcribed verbatim.

\section{RESULTS}

This section is structured into three sub-sections, which correspond to the three study objectives.

\section{Objective 1: Design characteristics of The Sonorous Paella project}

The idea for The Sonorous Paella project arose during the launching event of a book, authored by Valencian writer Josep Piera, related to the Valencian paella. A dialogue between the writer and the first author motivated the design of a creativity-fostering project centered on this gastronomic theme. 


\section{Provision of a graphic music score as creativity trigger}

The first author designed a graphic score (Figure 1), which was utilized as the project's creative trigger. The score was prepared in advance on a wall slate within the music classroom. Its size was large ( 6 meters long $\times 3$ meters wide). It had four sections, each of which represented in a separate quadrant on the plane, namely: Preparation, Stir-fry, Boiling, and Tasting. The score combined both figurative and abstract elements. The figurative elements involved drawings of objects and utensils commonly utilized during the four preparation stages for this recipe. The abstract elements (signs, strokes, lines, dots, etc.) symbolized the lunch ritual as a social event. The score designer aimed to foster introspective perspectives and multiple interpretations, in order to seek collective negotiations.

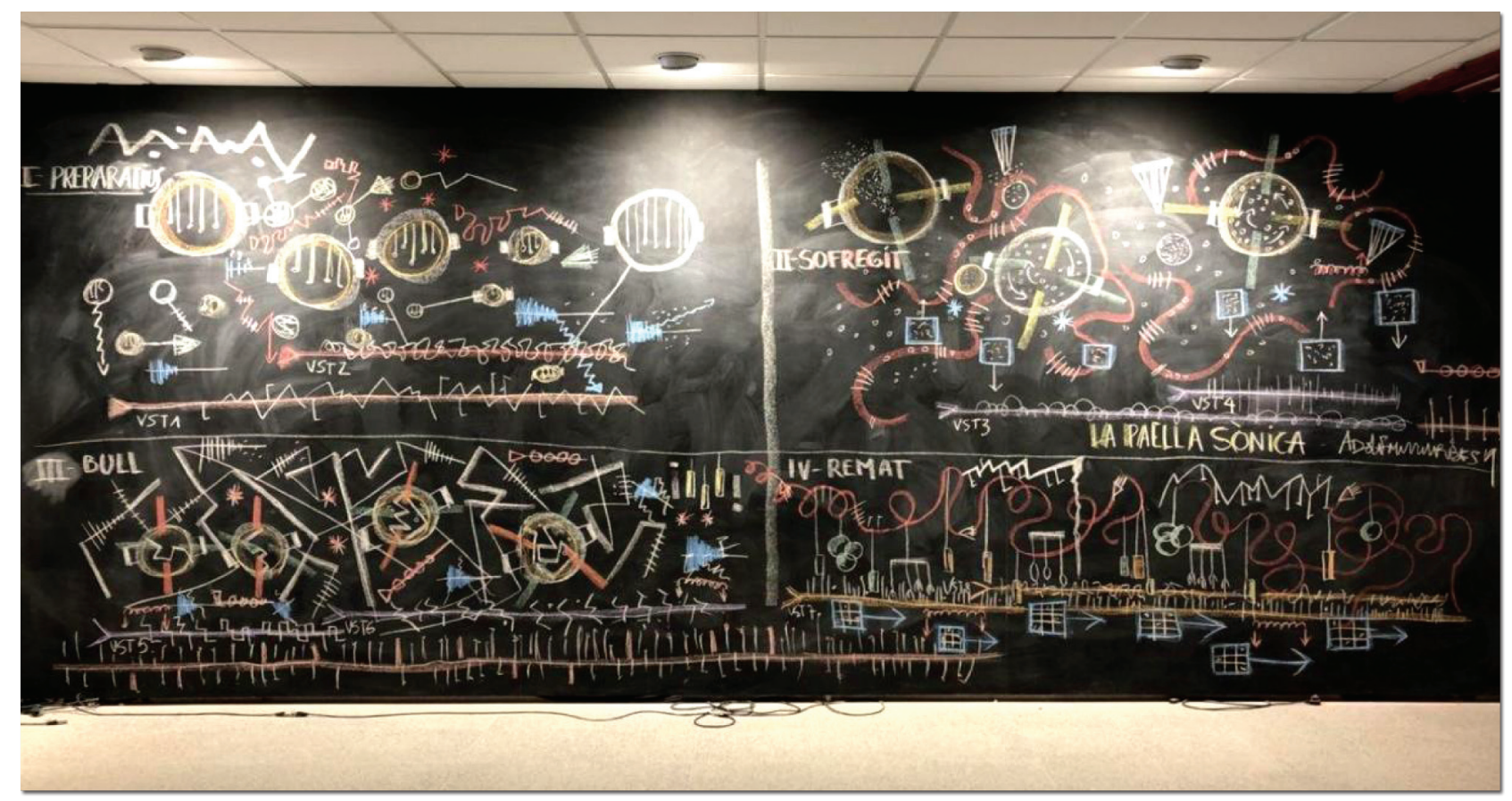

Figure 1. Graphic score provided (chalk on blackboard)

Participants were asked to create a collective interpretation of the graphic score, working together thorough various sessions and rehearsals, and then perform in the final concert.

\section{Multiple instruments, everyday objects, and ICT devices}

The participants were provided with acoustic instruments (transverse flute and electric guitar), a percussion set comprising everyday objects, and ICT devices (computers and mobile phones; see Figure 2). The percussion set included many of the kitchen utensils commonly utilized to cook paella, specifically five pans of different sizes, glass bottles, plates, glasses, crystal glasses, cutlery, a metal beer barrel, large cans of olives, small logs of wood, docks, water, rice, and plastic to simulate the sound of fire. Objects and instruments were given to participants from the beginning of the project, which contributed to create a friendly and hands-on environment. 


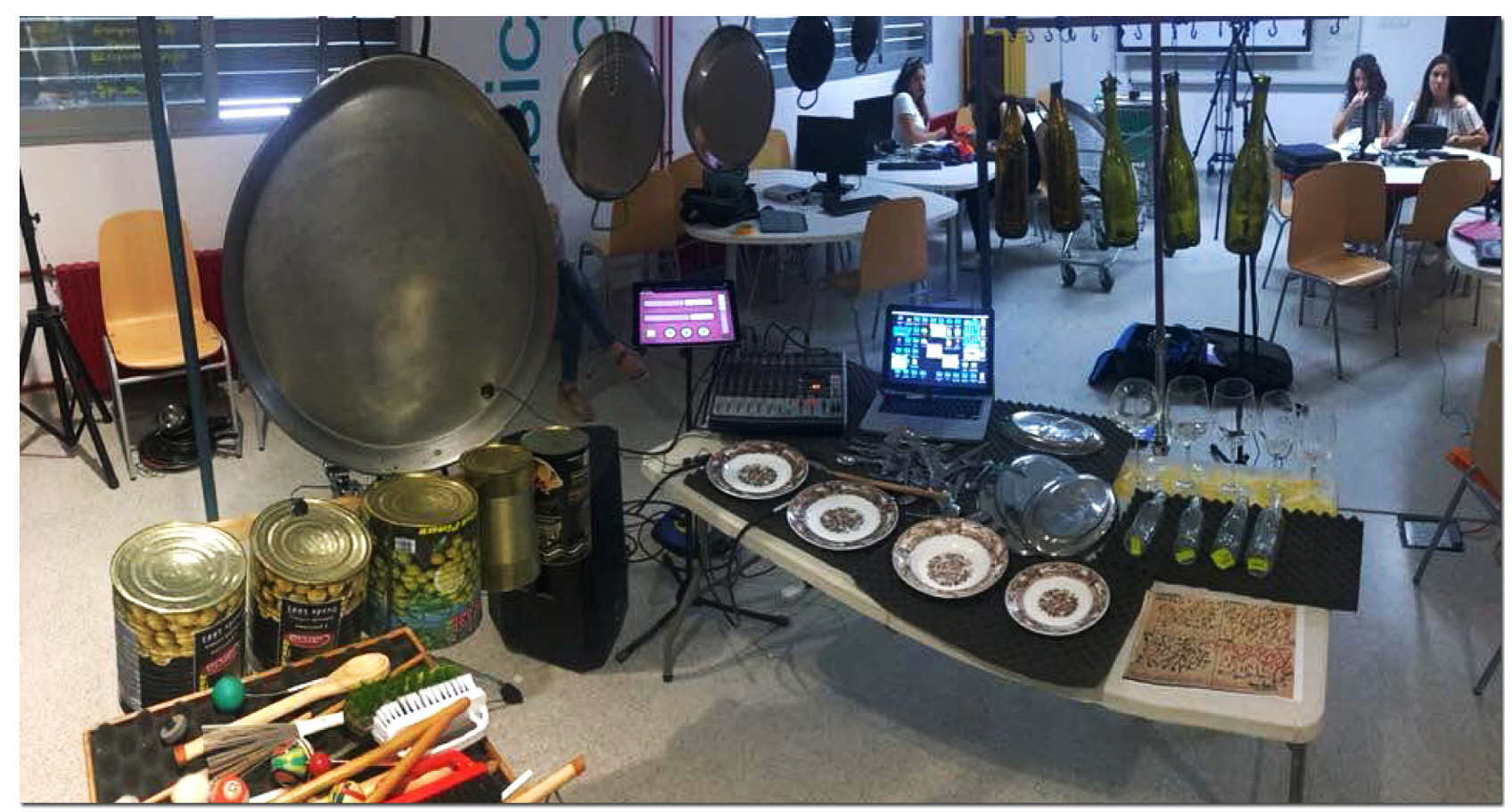

Figure 2. Instruments, everyday objects, and ICT devices

\section{Flexible classroom equipped with ICT devices}

The classroom had built-in equipment and movable furniture to flexibly work in teams of up to six people (Figure 3). It could be used as a music laboratory, as a performing stage, or as an empty room to facilitate social interaction. Each working station had a computer equipped with free and commercial audio and visual software. All computers were connected to a central mixing board, which allowed for reproduction and recording. The ICT resources available, therefore, allowed participants to engage in multiple tasks (e.g., usage of sensors and microphones, experimentation with objects and instruments, digital recording).

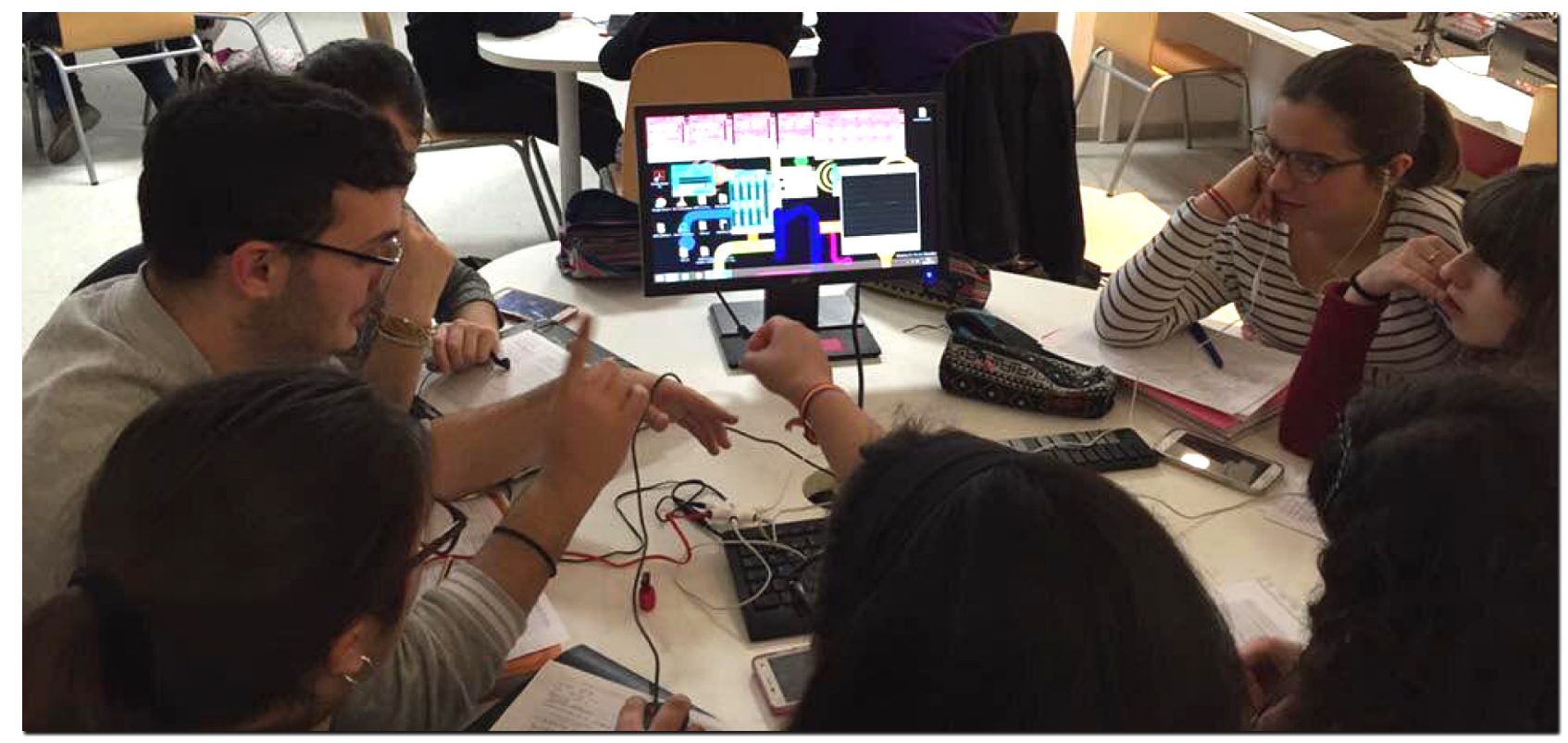

Figure 3. Classroom being used as a music laboratory 
All the instruments and everyday objects provided were electronically processed in real time using Soundcool ${ }^{\circledR}$ (Murillo, Riaño, \& Berbel, 2018). Soundcool is a free software designed with MAX MSP programming. It allows mobile devices (e.g., smartphones, tablets) to function as independent electronic instruments, or as effect processors (Reverb, Delay, Pitch, etc.) applied to acoustic instruments. The interface of Soundcool (see Figure 4) is a modular system visualized and managed from a computer, connected with mobile devices via WIFI. Soundcool significantly expands the aesthetic possibilities of sound, offering an array of sonorous choices (Berbel, Murillo, Sastre, \& Riaño, 2017).

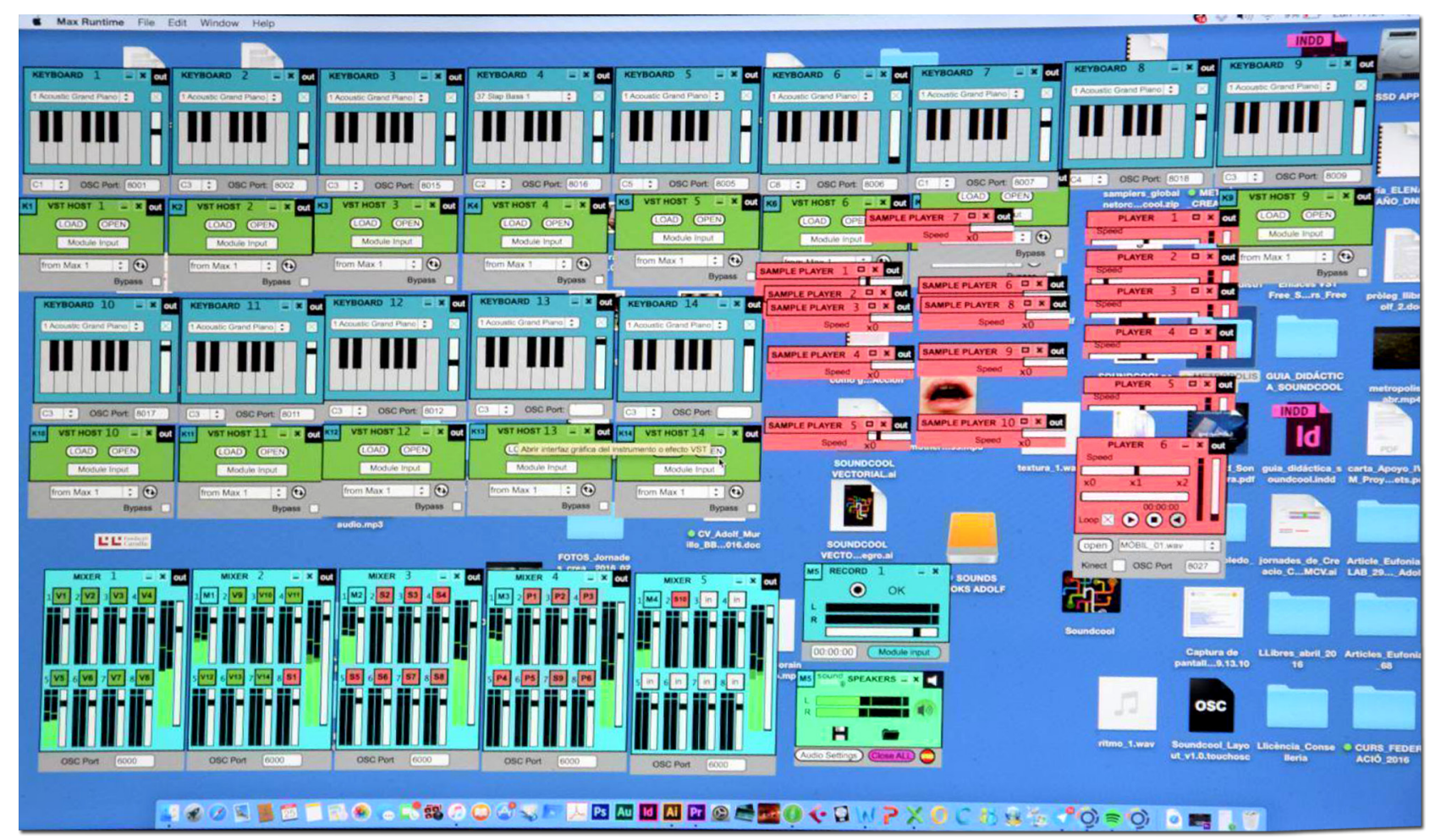

Figure 4. Soundcool interface

\section{A simple prompt and clear division of labor}

As mentioned, the project involved six 50-minute sessions and three 60-minute rehearsals, spanned over a period of 1.5 months. The participants were asked to create an original sound production and then perform The Sonorous Paella in a public concert. Once the graphic music score was shown to the participants, they embarked on a negotiation process aimed at collaboratively deciding how to decode and interpret each section. The participant observer: explained the design concept underlying the score; encouraged participants to discuss the melodic, rhythmic, and expressive possibilities within each section, and emphasized that graphic notation was open to multiple creative interpretations; and facilitated autonomy and freedom in collaborative decision-making. In turn, the participants (students and adults) were asked to: contribute their own ideas about the melodic, rhythmic, and expressive resources that could be used to interpret the figurative and abstract score notations; undertake multiple sound tests, exploring and playing the 
various instruments and objects available; and make collaborative decisions on how each section would be performed.

\section{Objective 2: The Sonorous Paella in the final concert}

We turn now to elaborating on the group's final performance, focusing on the most important interpretative decisions that were made collaboratively. The duration of the entire piece was 14'32". In the concert, the two professional musicians played percussion instruments and the transverse flute, respectively, and one of the students played the guitar. The other students used ICT devices (tablets, computers, mobile phones) to provide sonorous backgrounds and multiple types of sound effects, as described below.

\section{Preparation}

In the Preparation section, which lasted 2'1" (Audio Track 1), the participants experimented with the instruments and objects available in the classroom, focusing on both intensity and timbre. In the beginning, the participants decided to play with relatively low intensities to create a mysterious atmosphere. The percussionist focused on various items of the percussion set (e.g., using different ways to hit the paellas and other containers), and then produced sounds with little pieces of firewood to mimic the act of setting a fire. The group decided to slowly increase the number of sound contributors throughout this first section, which led to richness of textures and colors. There were short dialogues among the three soloists (percussion, transverse flute, and guitar). At some point of the performance, the figurative references in the graphic score became secondary and all participants began to explore the expressive possibilities of the instruments and objects at hand. The sonorous backgrounds produced by the ICT devices led to an acoustic climax, with a notable increase of intensity. Finally, the percussionist and the flautist processed their own acoustic instruments electronically in real time, which indicated the transition to the second section.

\section{Stir-fry}

The duration of the Stir-fry section was 3'37" (Audio Track 2). This section was significantly brighter and more melodic than the previous one. The percussionist indicated the beginning by dropping rice inside a metallic container. Subsequently, the other group members produced all sorts of grain-like sounds, which were intended to resemble the act of stir-frying rice. For example, some participants shook containers of different sizes and materials with rice inside. Others imitated the sound of rice being stir-fried by producing rhythmic and melodic motives with their instruments: the flautist played trills, the student guitarist contributed sounds based on extended techniques, and the rest performed short sounds electronically with their ICT devices. In the final part of this section, the flutist performed a solo and the percussionist provided the accompaniment, and there were also certain dialogues between instruments. 


\section{Boiling}

The Boiling section lasted 5'48' and it was characterized by timber richness (Audio Track 3). All participants intervened at the same time, producing intense dynamic and rhythmic contrasts and variations. This was their way to recreate the process of boiling water, which is necessary to cook the ingredients. Students produced drone-based sounds with their mobile devices, using sustained sounds, notes, and tone clusters. They produced rhythmic motives with fast tempos, as well as short sounds. In the middle of the section, the musical tension increased and reached a climax due to the sonorous dialogues and rhythmic loops established among some of the students. This was followed by an improvisation by the percussionist. In view of the resulting sonorous landscape, the flautist contributed different sounds based on extended techniques, in a constant improvised dialogue with the percussionist.

\section{Tasting}

The Tasting section, which lasted 2'53" (Audio Track 4), was characterized by ethereal sounds. It radically contrasted with the sonorous intensity and tension of the prior section. The intent was to reflect the pleasure involved in the ritual of coming together around the table to have lunch and finally taste a delicious, warm paella. The percussionist began by exploring hanging bottles, and then subtly hitting plates, glasses, and spoons. Subsequently, the flautist played a solo. A student contributed drone sounds based on a series of improvised chords played by the guitarist. The flautist joined the sonorous landscape again by contributing a soft melody. Finally, all the participants produced a pronounced diminuendo, until the only remaining sound was the one produced by the percussionist, while rubbing the rim of a glass with water.

\section{Objective 3: Participants' Perceptions and Opinions}

As mentioned, we interviewed all participants (students and adults) to investigate their perceptions of and opinions about The Sonorous Paella project. The following three sub-sections condense the main themes that emerged from the transcripts. The quotes included here were selected for being either representative (similar to what most participants expressed) or unique (different from what most participants said). All names are pseudonyms.

\section{The Value of Having Students and Adults Working Together}

The participants alluded to the feeling of belonging to a group. While the group was heterogeneous in nature, they expressed that differences in age, background, or status did not impede them from working together and establishing collaborative relationships based on mutual respect. Josep (student) said: "Having a good relationship, as the one we had in these past weeks, is fundamental and very helpful to ensure that the group comes up with something good, a good result." Similarly, Joan (student) shared: "The adults have been incredibly open to our ideas. Because of that, we've felt totally engaged not only in the project itself, but in something much bigger... We felt like, as in... like this is a group." 
The professional musicians (percussionist and flautist), the artist-in-residence, and the music educator commented that they had developed a very special "creative complicity" with the students, which they regarded as crucial to the success of the project. María (flautist) elaborated on the benefits this mutual understanding may bring about: "For students, the opportunity to construct something alongside professionals, working at the same level, is very positive. These experiences move students closer to creativity, normalize and demystify the arts, and make arts more human to them." In the same vein, Pablo (artist-in-residence) said: "In this project, we all have been partners. We've made joint decisions and had the feeling of being a group that is united for a common goal."

Due to the experimental nature of the project, the participants offered intuitive solutions and made decisions during working sessions, rehearsals, and in the final concert. Participants with and without musical background seemed to differ in how they addressed creative processes. For example, Pablo (artist-in-residence) shared the following:

Students with some musical background find it harder to solve musical challenges that can't be solved with traditional methods, the ones they already know, and they kind of freeze or don't get to find out new perspectives. In contrast, students with no musical background keep searching, they are much more open to try out crazy things.

When discussing the topic of making errors, students with no musical background expressed that not achieving the desired result triggered further creativity in them and that the notion of error makes no sense in contemporary music. For example, Cristina said "I do not freeze when experience challenges with this kind of music, because challenges always allow me to find new solutions," while Laura stated "I always continue to try and try new things until I find something I like." Vicent commented that "improvising and making all kinds of errors is the best way to go in this music," and Luisa even expressed that "it is creative to incorporate errors as part of the collaborative composition".

\section{Advocating for Contemporary Musical Languages and the Graphic Score as a Creative Trigger}

The participants pointed out that their experience in the project allowed them to broaden their musical preferences and adopt disruptive and transgressive roles in the music education classroom, which they greatly enjoyed (especially students). For example, Silvia (student) commented the following:

Making music this way allows me to understand and accept other kinds of music that in the past I wouldn't have recognized as music. Some of the sounds we have created have been surprising to me, and expanded my vision of what music is about. I felt this was our own creation. 
Similarly, Juan (student) stated that "in [his] opinion, just the fact of initiating a project in which the goal is to create new sounds to express something is already music, that's already art." These ideas were also mentioned by the adults. For example, the artist-in-residence said:

This kinds of experiences for students with no musical background may seem more limited regarding the learning of basic concepts and sound quality, but in fact, these music genres carry less prejudices. This is a lot better in terms of transgressing and forgetting conventionalisms and musical precepts that are routed in old traditions.

Most students also expressed having developed higher level of openness towards sound exploration. The project allowed them to learn that contemporary musical languages are equally valuable as other musical styles, and that "it is good to be willing to explore all different genres" (Silvia). Cristina (student) commented: "to those classmates who are reluctant to contemporary music, I would tell them that there are many ways to make music, not just classical. I encourage them to discover new ways to understand music and open their minds."

Participants perceived the graphic score to be much more than a mere visual guide. Rather, it was perceived as a tool with the potential to foster social interaction, and as a result collaborative musical creativity. Pablo (artist-in-residence) mentioned that the graphic score contributed to breaking with the view of a conventional music lesson and gave rise to a different kind of learning dynamic. Moreover, he expressed that "the graphic score changed the dynamic of all people looking to the teacher, and instead prompted participants to look at one another, changing the unidirectionality that characterizes conventional music lessons." Further still, the artist-in-residence referred to the score as a representation capable of fostering communication, debate, and consensus among participants. "This is an unknown language. Codes have no unique interpretations, and this is precisely what forces people to discuss different perspectives, debate with others, and then reach joint decisions" (Pablo). In this connection, Beatriz (music educator) expressed: "What is important is that we've created music, that we've been able to make an original piece that belongs to all of us."

Other participants also elaborated on the affordances and benefits of the graphic score. Josep (student) stated that "it is amazing that a simple score created with lines, drawings, and colors may contain so much information. The fact that each person can arrive at different solutions from the same symbol has been a very rich experience." In the same vein, Carlos (percussionist) commented: "The score is an open-ended framework, as not everything can be represented and coded. It is a guide that leaves room for freedom and individual interpretation." Finally, some participants expressed that the graphic score contributed to enhancing active listening. For example, María (flautist) explained: "In this experience, listening needs to be creative and meaningful because there's not an established reference frame. All participants need to listen actively to come up with a collaborative creation." Similarly, Josep (student) pointed out that "the score has allowed me to listen to the contributions of each participant, adapting myself and being aware of how the performance unfolds." 


\section{Innovative Classroom and the use of Technology}

Participants indicated that having an innovative classroom to carry out the project was an important element that facilitated and stimulated collaborative creativity, interaction and freedom. All students reflected on this matter. In Cristina's opinion, "Space influences a lot, because we had a very inspiring environment, very different compared to the typical white classroom with individual and separated desks and chairs." Similarly, Laura commented that "the classroom we had influenced very positively, because its characteristics incited us to adopt a receptive attitude for collaborative creation." Paula went even further: "This classroom is the type of place where students feel truly free, secure to come up with new stuff, a place to show our feelings without being judged... and this gives us security to be ourselves."

Furthermore, the participants expressed that the materials and resources available, their easy accessibility, the movable furniture, and even the decoration of the classroom were factors that contributed to a positive learning experience. For example, Carlos (percussionist) shared, "I think this classroom is a very suitable setting for multidisciplinary projects that require adaptability and flexibility. Having a versatile classroom really helps." Consistently, Joan (student) explained the following:

There are two factors that have positively influenced my experience: one is the decoration and futurist style of the class, which creates a completely different environment compared to a typical class, and also the resources and instruments used, such as computers, microphones, audio mixers, conventional instruments, and also digital tools.

Participants also commented on the role of ICT in the project. Some students valued the ease and simplicity of the devices utilized. Cristina, for example, stated that "the technologies we have used allow everyone to make music. Skills are not really required, so I think anyone can participate, which is great!" Based on their positive experience in this project, the adults lamented on the lack of technology integration in many music classrooms. This was the case of Beatriz (music educator), who stated: "What this project requires at the technological level should be present in all secondary school music classrooms, but unfortunately I don't think this approach is still common in most schools." The importance of democratizing technology in music education was brought up by others, including Carlos (percussionist), who said: "With The Sonorous Paella, I have realized that normalizing technology in contemporary creative processes is absolutely necessary."

\section{DISCUSSION}

Research on musical creativity has shown that projects involving collaboration yield better student learning outcomes (Muhonen, 2014; Sawyer, 2004), that projects may become even more creativity-fostering when other agents (e.g., artists, musicians, teachers) actively collaborate with students (Lage \& Cremades, 2019; Ruokonen, 2018), and that it is urgent to enhance the teaching and learn- 
ing of music in formal education settings (Cremin \& Chappell, 2019). However, due to numerous reasons, music teachers around the world continue to find it challenging to design and implement curriculum units that foster collaborative musical creativity (Bautista et al., 2018; Tan et al., 2019; Veloso, 2017). It is therefore relevant to conduct classroom-based research that provides music teachers with pedagogical insights (Kelly, 2020).

Objective 1 was to describe the design characteristics of The Sonorous Paella. Firstly, this project engaged a participant observer who documented and facilitated its implementation (Dezuanni \& Jetnikoff, 2011) and was strongly supported by the leadership of the school where it was conducted (Dezuanni \& Jetnikoff, 2011). One key characteristic was the use of a graphic score based on unconventional notation, which was utilized as a creativity trigger. This pedagogical decision resonates with Brondum (2018) and Reybrouck et al. (2009), who demonstrated that unconventional notation is more suitable to facilitate sound exploration, experimentation, and improvisation. A second characteristic was the inclusion of both students and adults (Lage \& Cremades, 2019), who were invited to collaboratively decode the score's symbols and come up with an original sound creation and performance. More specifically, our approach resonates with Ruokonen (2018), who stressed the importance of involving teachers and practicing artists in projects intended to foster students' creative thinking.

A third important characteristic was the provision of multiple types of sonorous resources, including acoustic instruments, everyday objects commonly used to cook a paella (utensils, pans, pots...), and ICT resources (computers, mobile devices, tablets; Murillo et al., 2018). The availability of multiple resources contributed to maximizing communication among the participants, as they had to make numerous decisions throughout the various working sessions and rehearsals (Bautista et al., 2018; Sawyer, 2004), and also expanded their expressive possibilities during the creative process (Bolton, 2008; Reese, 2001). Finally, another key characteristic relates to the physical environment in which the project was undertaken. The participants worked in a large classroom where they could flexibly rearrange the display of the materials and resources available, brainstorm and try out ideas, hold debates, and make group decisions (Vecchi, 2010). In sum, drawing on a solid body of prior music creativity research (Beghetto \& Kaufman, 2014; Muhonen, 2014; Nouri \& Farsi, 2018; Reybrouck et al., 2009; Ruokonen, 2018; Vecchi, 2010; Veloso, 2017), we argue that the combination of the above-mentioned characteristics had the potential to facilitate collective musical creativity.

Objective 2 was to describe the sonorous outcome of The Sonorous Paella, as performed in the final concert. The collaborative performance followed the four sections proposed in the graphic score: Preparation, Stir-fry, Boiling, and Tasting (Figure 1). In the Preparation section, the three soloist instruments (guitar, transverse flute, and percussion) conveyed meanings related to specific symbols in the graphic score. Concurrently, the students in charge of the ICT devices produced background sounds that contributed rich timbrical textures (Berbel et al., 2017), resembling the sound of a busy kitchen. In the Stir-fry section, the participants focused on the small dots represented in the graphic score, which were interpreted as rice grains. The resulting sounds were short, rhythmic, 
and somewhat sharp. The Boiling section was interpreted as the climax of the paella's elaboration process, as it is when hot water comes in contact with ingredients that are being stir-fried and everything starts to boil. The score displayed multiple kinds of lines, strokes, colors, and shapes, which participants interpreted with vibrant and high intensity sounds. The performance reflected this richness by using complex timbrical textures, dynamic and rhythmic variations, a variety of sonorous effects, sounds clusters, contrasting tensions, extended techniques, and dialogues among the instruments involved. Finally, the Tasting section was characterized by its radical contrast with the prior sections. The waiving lines were taken as the predominant element, being interpreted as soft melodic lines, which resembled the pleasure of enjoying this dish with others. Based on the quality and originality of the group performance in the final concert (Audio Tracks 1-4), we infer that the key characteristics and pedagogical features of The Sonorous Paella project were effective in terms of fostering collaborative musical creativity. Our approach is aligned with authors such as Veloso (2017), Muhonen (2014), and Sawyer (2004), who posited that pedagogical experiences that involve collaboration and social interaction lead to better musical learning processes and outcomes.

Finally, in response to Nielsen's (2013) work, Objective 3 was to describe the participants' perceptions and opinions about their participation in The Sonorous Paella. The participants expressed that collaborative interactions had been very positive and productive in terms of the group's musical creativity. They all felt free to contribute their ideas and openly share their opinions, which allowed the group to reach creative solutions (Jacobs, 2018). Moreover, all participants shared that this project had helped them to open their minds towards contemporary music styles (Berbel et al., 2017). Opportunities to explore, experiment, and improvise with sound were valued very positively, in particular by students, as they had had limited experience in these matters before. The graphic music score was perceived as a tool that enhanced creativity and collaboration, similar to the conception of its author. The various symbols were utilized as an inspiring working guide, as an open-ended framework for collaborative self-expression (Bergstrom-Nielsen, 2010). Participants pointed out that the technological tools provided were useful and easy to use. However, they also expressed that such tools are still seldom used to foster creativity in many music classrooms, and hence there is need to make their usage more widespread (Hoffmann et al., 2016). Finally, participants expressed favorable perceptions regarding the use of physical space. In their opinion, the classroom setup was conducive for creative processes, as it was easy to flexibly rearrange the display of the instrumental set, which facilitated social interactions, communication, and good classroom climate (Cobo, 2016).

Overall, the participants demonstrated to have positive perceptions of and opinions about The Sonorous Paella project and its various design characteristics. They were able to discuss, share their ideas, and make joint decisions about the meanings and potential sonorous interpretations of the graphical symbols of a contemporary music score (Brondum, 2018; Reybrouck et al., 2009). Interestingly, while questions in our interview protocol focused on both processes and outcomes, the participants' responses tended to focus primarily on the former. This resonates with Runco (2007), who highlighted the centrality of creativity processes in creativity-fostering pedagogies (Runco \& 
Jaeger, 2012). Similarly, most participants in our study emphasized the importance of working collaboratively, feeling that everyone belongs to the team, regardless of their roles as students, professional musicians, or teachers, and that everyone has ideas worth sharing. Everyone was considered to be equal and in the same plane of action, with no hierarchies (Irwin, 2013; Lage \& Cremades, 2019). The positive classroom climate that was created, based on active listening and dialogue, was therefore key in terms of generating an environment conducive to collaborative musical creativity (Beghetto \& Kaufman, 2014; Kelly, 2020; Vecchi, 2010). Moreover, the positive perceptions of our participants regarding the classroom environment are aligned with Nouri and Farsi (2018), who have recently discussed the key role that physical spaces can play as facilitators of creativity, adaptability, flexibility, and sensory sensitivity (Przyborowska \& Błajet, 2020).

\section{LIMITATIONS, FUTURE RESEARCH, AND IMPLICATIONS}

The intent of this study is not to show that The Sonorous Paella was a perfect project, applicable in every music classroom. Instead, the intent is to illustrate how collaborative projects based on a series of key design characteristics (all discussed in our literature review) may foster collaborative musical creativity (Bautista et al., 2018; Muhonen, 2014; Tan et al., 2019; Veloso, 2017). Because this study is based on a single case, it would be important to investigate the feasibility and effectiveness of similar collaborative projects when implemented in different socio-cultural contexts and educational levels. We claim that music classrooms around the world are in urgent need for outof-the-box creativity-fostering pedagogies, in order to break with reproductive and conventional approaches to music teaching and learning (Johnson, 2009; Lines, 2009). Experiences involving collaborative exploration, experimentation and creation are aligned with contemporary educational paradigms in the area of creativity for the 21st century (Tan et al., 2019).

This study was conducted to illustrate how the design characteristics of a collaborative music project may lead to creative processes and outcomes (Runco, 2007; Runco \& Jaeger, 2012). Regarding implications for future research, it would be important to conduct more qualitative studies to further illustrate how to design, implement, and evaluate multidisciplinary projects that foster collaborative musical creativity (Berbel et al., 2017; Brondum, 2018; Reybrouck et al., 2009), and also to better understand how students, teachers, and artists experience their learning in such experiences (Lage \& Cremades, 2019; Tan et al., 2019). Much needs to be done to ensure that students in contemporary classrooms participate in projects and activities that foster their musical creativity. We encourage both school administrators and music teachers to work together to enhance curriculum and practices, moving towards a more creative music education for all (Tan et al., 2019). 


\section{References}

Bautista, A., Tan, L.S., Ponnusamy, L.D., \& Yau, X. (2016). Curriculum integration in arts education: Connecting multiple art forms through the idea of 'space'. Journal of Curriculum Studies, 48(5), 610-629. https://doi. org/10.1080/00220272.2015.1089940

Bautista, A., Toh, G.Z., Mancenido, Z., \& Wong, J. (2018). Student-centered pedagogies in the Singapore music classroom: A case study on collaborative composition. Australian Journal of Teacher Education, 43(11), 1-25. Retrieved from https://ro.ecu.edu.au/ajte/vol43/iss11/21. https://doi.org/10.14221/ ajte.2018v43n11.1

Beghetto, R.A., \& Kaufman, J.C. (2014). Classroom contexts for creativity. High Ability Studies, 25(1), 53-69.

Bergstrom-Nielsen, C. (2010). Graphic notation-the simple sketch and beyond. Nordic Journal of Music Therapy, 19(2), 162-177. https://doi.org/10.1080/08098131.2010.497227

Berbel, N., Murillo, A., Sastre, J., \& Riaño, M.E. (2017). Sound creation and artistic language hybridization through the use of the collaborative creation system: Soundcool. Turkish Online Journal of Educational Technology TOJET, 4(3), 199-210.

Bolton, J. (2008). Technologically mediated composition learning: Josh's story. British Journal of Music Education, 25(1), 41-55. https://doi.org/10.1017/S0265051707007711

Brondum, L. (2018). Graphic notation, indeterminacy and improvisation: Implementing choice within a compositional framework. Open Cultural Studies, 2(1), 639-653. https://doi.org/10.1515/culture-2018-0058

Burnard, P., Murphy, R., \& Akuno, E. (2017). Enseñar música de forma creativa [Teaching Music Creatively]. Madrid, España: Ediciones Morata.

Cobo, C. (2016). La innovación pendiente: Reflexiones (y provocaciones) sobre educación, tecnología y conocimiento [Pending innovation: Reflections (and provocations) on education, technology and knowledge]. Montevideo, Uruguay: Penguin Random House.

Corradini, M. (2011). Crear. Cómo se desarrolla una mente creativa (Vol. 2) [Creating. How to develop a creative mind (Vol. 2)]. Madrid, España: Ministerio de Educación Cultura y Deporte, Instituto de Formación del Profesorado, Investigación e Innovación Educativa (IFIIE).

Creely, E., Henriksen, D., \& Henderson, M. (2020). Three Modes of Creativity. The Journal of Creative Behavior.

Cremin, T., \& Chappell, K. (2019). Creative pedagogies: A systematic review. Research Papers in Education, 33. https://doi.org/10.1080/02671522.2019.1677757

Creswell, J.W. (2013). Research design: qualitative, quantitative, and mixed methods approaches (Vol. 4th). Thousand Oaks (California): Sage.

De Vries, M.J. (2016). Teaching about technology: An introduction to the philosophy of technology for non-philosophers. Dordtecht, The Netherlands: Springer.

Delalande, F. (2008). Un millón de compositores. Madrid, España: Ministerio de Educación.

Dezuanni, M., \& Jetnikoff, A. (2011). Creative pedagogies and the contemporary school classroom. In J. SeftonGreen, P. Thomson, K. Jones, \& L. Bresler (Eds.), Routledge International Handbook of Creative Learning (pp. 264-272). London, UK: Routledge.

Elkoshi, R. (2015). Children's invented notations and verbal responses to a piano work by Claude Debussy. Music Education Research, 17(2), 179-200. https://doi.org/10.1080/14613808.2014.930116

Hall, C., \& Thomson, P. (2017). Creativity in teaching: what can teachers learn from artists? Research Papers in Education, 32(1), 106-120. https://doi.org/10.1080/02671522.2016.1144216

Hemlin, S., Allwood, C.M., \& Martin, B. (2008). Creative knowledge environments. Creativity Research Journal, 20(2), 196-210. doi:10.1080/10400410802060018

Hoffmann, J., Ivcevic, Z., \& Brackett, M. (2016). Creativity in the age of technology: measuring the digital creativity of millennials. Creativity Research Journal, 28(2), 149-153. https://doi.org/10.1080/10400419. 2016.1162515 
Irwin, R.L. (2013). Becoming A/r/tography. Studies in Art Education, 54(3), 198-215. https://doi.org/10.1080/00 393541.2013.11518894

Jacobs, J. (2018). Intersections in Design Thinking and Art Thinking: Towards Interdisciplinary Innovation, Creativity. Theories - Research - Applications, 5(1), 4-25. https://doi.org/10.1515/ctra-2018-0001

Johnson, R. (2009). Critically reflective musicianship. In T.A. Regelski \& J.T. Gates (Eds.), Music education for changing times (pp. 17-26). Dordrecht, The Netherlands: Springer.

Kelly, R. (2020). Collaborative creativity: Educating for creative development, innovation and entrepreneurship. Alberta, Canada: Brush Education.

Kokotsaki, D. (2011). Student teachers' conceptions of creativity in the secondary music classroom. Thinking skills and creativity, 6(2), 100-113. https://doi.org/10.1016/j.tsc.2011.04.001

Lage, C., \& Cremades, R. (2019). Group improvisation as dialogue: Opening creative spaces in secondary music education. Thinking skills and creativity, 31, 232-242. https://doi.org/10.1016/j.tsc.2018.12.007

Lines, D. (2009). La educación musical para el nuevo milenio. Madrid, España: Morata.

Martin, J. (2013). Tradition and transformation: Addressing the gap between electroacoustic music and the middle and secondary school curriculum. Organised Sound, 18(2), 101-107. https://doi.org/10.1017/ S1355771813000022

Martin, L., \& Wilson, N. (2017). Defining creativity with discovery. Creativity Research Journal, 29(4), 417-425. https://doi.org/10.1080/10400419.2017.1376543

Muhonen, S. (2014). Songcrafting: A teacher's perspective of collaborative inquiry and creation of classroom practice. International Journal of Music Education, 32(2), 185-202. https://doi.org/10.1177/025576141350 6657

Mullet, D.R., Willerson, A., Lamb, K.N., \& Kettler, T. (2016). Examining teacher perceptions of creativity: A systematic review of the literature. Thinking skills and creativity, 21, 9-30. https://doi.org/10.1016/ j.tsc.2016.05.001

Murillo, A., Riaño, M.E., \& Berbel, N. (2018). Perception of the use of 'Soundcool' as a proposal for intervention in the creation of sound and in the development of teaching competences. An exploratory study on pre-service teacher education. Psychology, Society and Education, 10(1), 127-146. https://doi. org/10.25115/psye.v10i1.1051

Nielsen, L.D. (2013). Developing musical creativity: Student and teacher perceptions of a high school music technology curriculum. Applications of Research in Music Education, 31(2), 54-62. https://doi.org/10.117 $7 / 8755123312473610$

Nouri, A., \& Farsi, S. (2018). The current state of arts education in Iran: A case study in two elementary schools using educational criticism. International Journal of Art and Design Education, 37(1), 125-136. https://doi. org/10.1111/jade.12151

Organization for Economic Co-operation and Development [OECD] (2018). The future of education and skills: Education 2030. Paris, France: OECD Publishing.

Przyborowska, B., \& Błajet, P. (2020). The Importance of Place in Creative Activity - a Proposal for an Integral Approach. Creativity. Theories - Research - Applications, 7(1), 27-37. https://doi.org/10.2478/ctra-20200002

Reese, S. (2001). Tools for thinking in sound. Music Educators Journal, 88(1), 42-53.

Reybrouck, M., Verschaffel, L., \& Lauwerier, S. (2009). Children's graphical notations as representational tools for musical sense-making in a music-listening task. British Journal of Music Education, 26(2), 189-211. doi:10.1017/S0265051709008432

Runco, M. (2007). Creativity. Theories and themes: Research, development and practice. San Diego, CA: Elsevier.

Runco, M., \& Jaeger, G.J. (2012). The standard definition of creativity. Creativity Research Journal, 24(1), 92-96. https://doi.org/10.1080/10400419.2012.650092 
Ruokonen, I. (2018). 'I - from dreams to reality': A case study of developing youngsters' self-efficacy and social skills through an arts educational project in schools. International Journal of Art \& Design Education, 37(3), 480-492. https://doi.org/10.1111/jade.12138

Sawyer, R.K. (2004). Creative teaching: Collaborative discussion as disciplined improvisation. Educational Researcher, 33(2), 12-20. https://doi.org/10.3102/0013189X033002012

Sawyer, R.K. (2007). Group genius: The creative power of collaboration. New York, USA: Basic Books.

Tan, A.-G., Yukiko, T., Oie, M., \& Mito, H. (2019). Creativity and music education: A state of art reflection. In T. Yukiko, A.G. Tan, \& M. Oie (Eds.), Creativity in music education (pp. 3-16). Singapore: Springer.

United Nations Educational Scientific and Cultural Organization [UNESCO] (2014). The challenges of creativity. Education, Research and Foresight: working papers, 1, 1-10.

Vecchi, V. (2010). Art and creativity in Reggio Emilia. Exploring the role and potential of ateliers in early childhood education. London, UK: Roudledge.

Veloso, A.L. (2017). Composing music, developing dialogues: An enactive perspective on children's collaborative creativity. British Journal of Music Education, 34(3), 259-276. https://doi.org/10.1017/ S0265051717000055

Zhang, G., Li, H., \& Yan, S. (2020). The Vital Few: Exploring the Role of Expertise in the Process of Team Creativity. The Journal of Creative Behavior.

(c) Copyright by Faculty of Education, University of Bialystok,

20 Swierkowa St., 15-328 Bialystok, Poland

tel. +48857457283

e-mail: creativity@uwb.edu.pl

http://www.creativity.uwb.edu.pl 